\title{
The Technology Application Aspect in Optimization of Islamic geometric patterns
}

\author{
Aya A. EL.Taweel ${ }^{1}$, Aliaa A. Mahmoud ${ }^{2}$ \\ 1. Aya Atef El.Taweel, Teaching assistant, Department of Architecture, Mansoura High Institute \\ of Engineering and Technology, Mansoura,Egypt, ataweel@mc.edu.eg \\ 2. Aliaa Abbas Mahmoud, Teaching assistant, Department of Architecture, Mansoura High \\ Institute of Engineering and Technology, Mansoura,Egypt,almahmoud@mc.edu.eg
}

\begin{abstract}
For centuries, Islamic geometrical patterns (IGPs) were designed and built to respond effectively and dynamically to people's physical, environmental, social, physiological and religious requirements at their time. The architects used to copy-paste various IGPs of the Islamic historical buildings in their design work without understanding the meanings and values that it holds. This way has often caused inappropriate use, regarding time-scale accuracy, architectural- style matching and even identity. In an attempt of handling this misunderstanding, there is a trend of combining technology applications in architecture to recruit IGPs design and maximize its purpose either function or decorative shape. For that, the research will analyze a number of buildings from different countries and cultures with IGPs applied in a technological way. The research proposes different technology techniques in dealing with IGPs in order to enhance the function and other purposes as possible as we can on a large scale.
\end{abstract}

Key Words: Islamic geometrical patterns, Technology application, Optimization, Function

\section{INTRODUCTION}

In Islamic architecture, the Geometric patterns are one of the ornamental elements as they are widely used as decorative elements over building elements. It is well known that the Islamic architecture is famous for glory, beauty, and balance which is based on the intellectual integration between mathematical and geometric sciences with art and architecture. Although, the suitability and appropriate use of these patterns are still ambiguous. (Abdullahi \& Embi, 2013)

The issue becomes more critical about the evolution of the Islamic architecture through the modern world as geometric pattern are copied to cover all surface of the building and the only changes that can be found are concerning using new materials and constructional method which help to rescale the patterns to cover larger scale than before. The "copy-pasting" patterns all over any surface without any understanding to the period-style, regional-style are the common technique in the modern architecture when it uses the IGPs. (Abdullahi \& Embi, 2013)

IGPs are often used inappropriately concerning the scale dimension and sitting inside frames. They often scaled and fitted without any attention to the broken shapes along edges of surfaces. An example of misuse of pattern scaling is at Persada Johor in Malaysia and Sultan Hassan II mosque in Morocco as shown in (Figure 1) where stars and polygon are roughly cut. These examples can be compared with elegant survived masterpieces such as Hakim Mosque of Isfahan (1656-62 CE) as shown in (Figure 2) that show suitable using of IGPs as an architect first analyze the surface geometry and then modified the patterns to fulfill the surface perfectly with minimum deformity along the edges. (Abas \& Salman, 1995) 


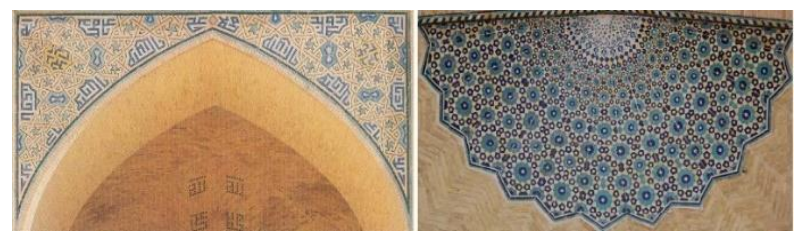

Figure 2: Hakim mosque of Isfahan in Iran 1662 CE (Abas \& Salman, 1995)

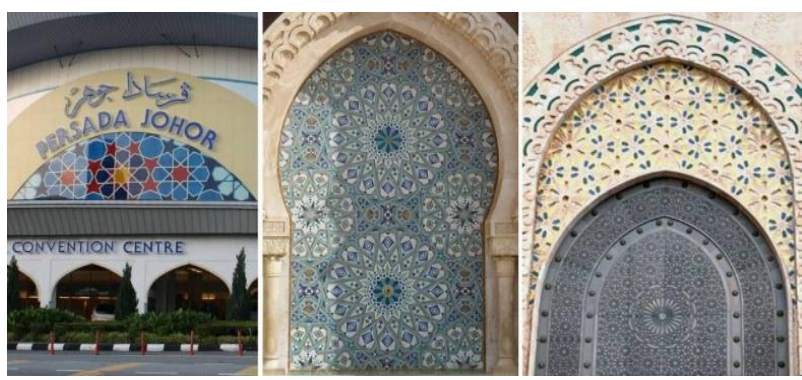

Figure 1: Persada Johor (left), Sultan Hassan II mosque (centre \& right) (Abas \& Salman, 1995)

Above examples show the necessity of studies toward establishing guidelines on use and suitability Islamic geometrical patterns in Islamic-inspired buildings. (Abas \& Salman, 1995)

\section{Types of IGPs}

The scope of this research does not concern the definitions and classifications of IGPs. Although, getting a brief of IGPs types is essential. Most of the IGPs are based on constructive polygons such as hexagon and octagon. Star-polygon will appear by connecting vertexes of these shapes which are considered as a fundamental element of IGPs. All patterns are based on hexagon come under 6-point geometric pattern. Also, patterns are further called as 8, 10, 12, 14, Point geometric patterns. (Aljamali \& Banissi, 2004)

\section{Methodology}

In an attempt to highlight the evolution using technology technique to maximize the usage with inspiring the traditional methods as Mushrabiya technique, a number of case studies will be analyzed. To ensure that relevant and appropriate building cases are selected, specific criteria were used in the selection process and their

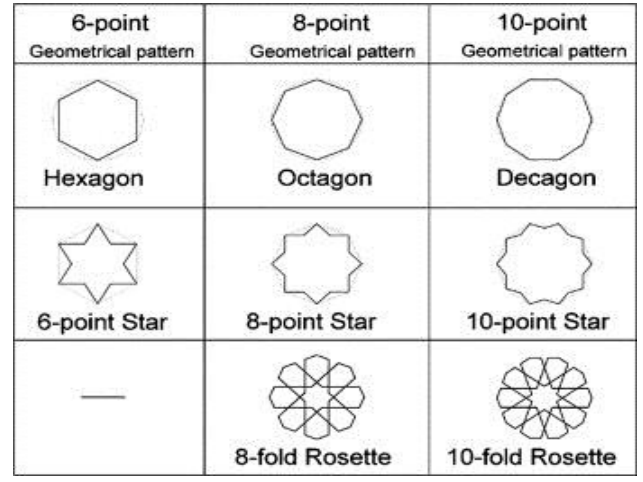

Figure 3: First level of IGPs classification (Aljamali \& Banissi, 2004) relation to the traditional technique of Mushrabiya as follows:

a. The buildings, in particular, should cover as much as possible the variety of climate condition as being in different countries.

b. The buildings should be already existing.

c. The buildings should achieve awards concerning the environmental aspect.

Taking these criteria into consideration, a systematic search through the various building and after holding the potential case study buildings with the selection criteria, three buildings were found to match the Mushrabiya technique sufficiently as mentioned in Table 1 below.

Table 1: The three selected building for the investigation.

\begin{tabular}{|c|c|c|}
\hline Project name & Al Bahar Towers & Arab World Institute \\
\hline Location & Abu Dhabi & France \\
\hline
\end{tabular}




\section{Mashrabiya Concept Evolution}

Mushrabiya is an expression given to a projection oriel window type that enclosed with a wood latticework located on the 2nd floor of the building. This type of projection is an element of traditional Arabic architecture used since the middle ages. Mushrabiya element has some major purpose including a social and environmental and architectural purposes. Concerning the social aspect, the privacy is an essential aspect of Arabic culture with offering a good view to the street without being seen. While in the environmental aspect, the wooden screen with openable windows give a hot summer sun protection while allowing the cool air flow.

Almashrabiya is an efficient passive design element that controls the passage of air current to reduce the temperature. It also reduces the reflected heat and solar radiation and allows air to pass through freely. In addition, it regulates the amount of day lighting passing to the internal spaces as shown in figure 4. It is designed with a small opening in the bottom part and larger in the higher to cause a fast air suction above the head without causing any uncomfortable. The architectural aspect, Mushrabiya is used to correct the footprint shape of the land due to irregular streets and also used to offer shadow zones under the Mushrabiya unit to the street. (Jehan, 2015)

With development and translation of tradition into modern facades with high technology or even dynamic facades, the role of Mashrabiya screen has changed from a layer to protect from outside views to an element that attracts the outside viewer. Moreover, modern sensor and technology allow keeping Mashrabiyas relevant well into the future, opening a fascinating way of dynamically controlling each shadow pixel to optimum controlling of shading and atmosphere. Also, designers have even transformed the vernacular wooden structure into high-tech responsive daylight system. (Jehan, 2015)

\section{Technology application aspect of IGPs Analysis}

\subsection{Al Bahar Towers}

- Overview

Al-Bahr Towers- the Abu Dhabi Investment Council's New Headquarters was an international competition. This competition won by AAedas-UK (now AHR) in Collaboration with Arup in 2007. Al-Bahr Towers are located in Abu Dhabi, United Arab Emirates. The building as shown in (Figure ) stands out with its fluid form honeycomb-inspired structure with its dynamic solar screen. The system kinetically responds to the sun's movement to offer the building its distinct identity. (Karanouh \& Kerber, 2015)

- Site analysis:

The location of Abu-Dhabi in a climate zone with extremely sunny and temperature reaching up to $49^{\circ}$ and the humidity up to $100 \%$ during summer. (Oborn, 2013)

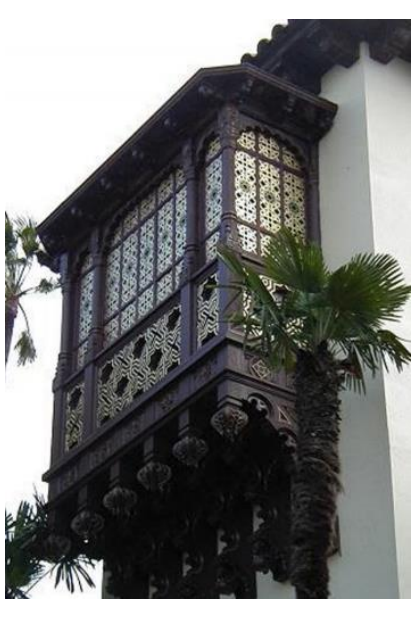

Figure 4: The traditional Mushrabiya

(Oborn 2013$)$

)
Figure 5: The Al-Bahr Towers is a
high-performance (Karanouh \& Kerber, 2015)

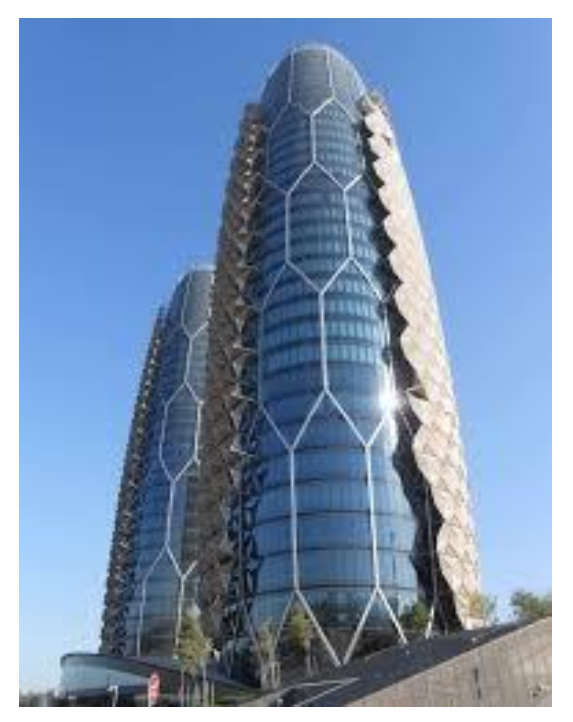

Kerber, 2015) 
- Concept:

Al-Bahr Towers draw inspiration from the combination of the past with the ornamental patterns and the future with its dynamic use of these pattern in an environmental way. The intention was set to explore bio-inspiration and guide examples designed its form inspired from cactus, pineapples, flowers and other natural systems. A cactus has umbrella-like features to protect its delicate weather-tight skin. Flowers open and close in response to changing weather conditions. The pineapple's hexagonal envelope covers a double-curved surface efficiently to embody these attributes in the towers design. (Cilento, 2014)

Islamic architecture is all about context embodied in optimizing performance; excessive exposure to direct solar rays is eliminated by using cooling courtyards, self-shading geometrices. Mushrabiya, as shown in (Figure 5), are made of IGPs. The towers concept is inspired from the Mushrabiya technique in eliminating the solar rays and achieving the occupant's privacy. (Cilento, 2014)
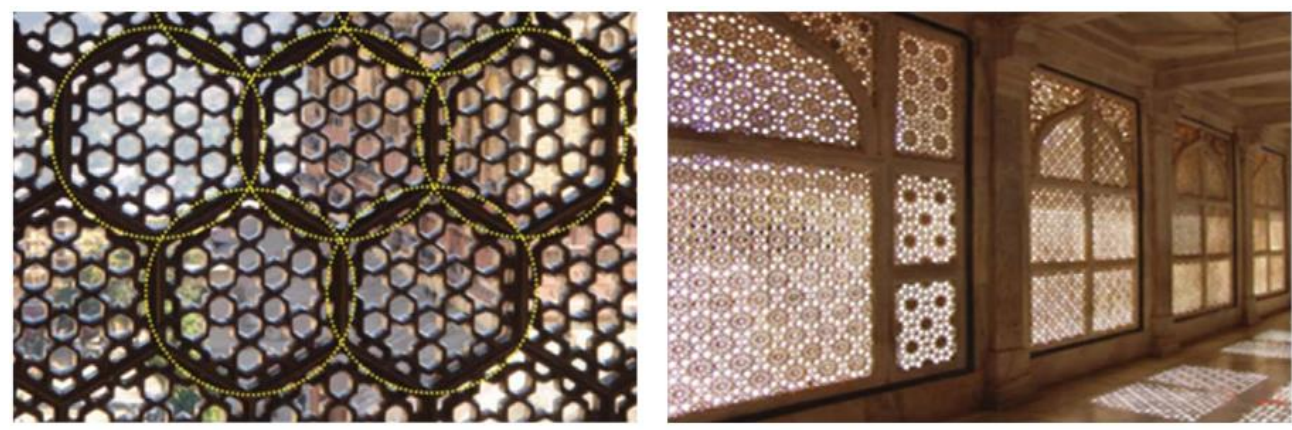

Figure 6: . Examples of this IGPs are found in mashrabiya, such as those applied in Sheikh Lotfollah Mosque in Isfahan, Iran (left) and the Taj Mahal (right). (Oborn, 2013)

- Technique of application:

The design of Towers is inspired by its context, taking into consideration the environment, tradition and technology aspect. In order to achieve this, a digital tools are used to automate the design and execution. These techniques including using to Algorithms, parametric design, Building Information Modelling (BIM), and production automation have integrated into the AEC industry. This has brought the highest degree of complexity to the creation of architectural ideas. (Karanouh \& Kerber, 2015)

- Dynamic mashrabiya

The dynamic Mashrabiya which acts as a solar screen is a unique automated feature with a comprised way of its triangular units like origami umbrellas as shown in (Figure ). These dynamic shading elements unfold to various angles related to the sun movement to optimize the solar exposure of the façade. The folding system transforms the shading screen from a seamless veil into a lattice-like pattern that, when necessary, provides either shade or light avoiding dark tinted glass and internal blinds that distort the appearance of the surrounding view. This system off ers a better admission of natural diff used light. This reduces the use of artificial light and the associated energy costs. Reduced solar gain on the main skin results in reduced aircooling loads, energy consumption, and plant room size. (Cilento, 2014)

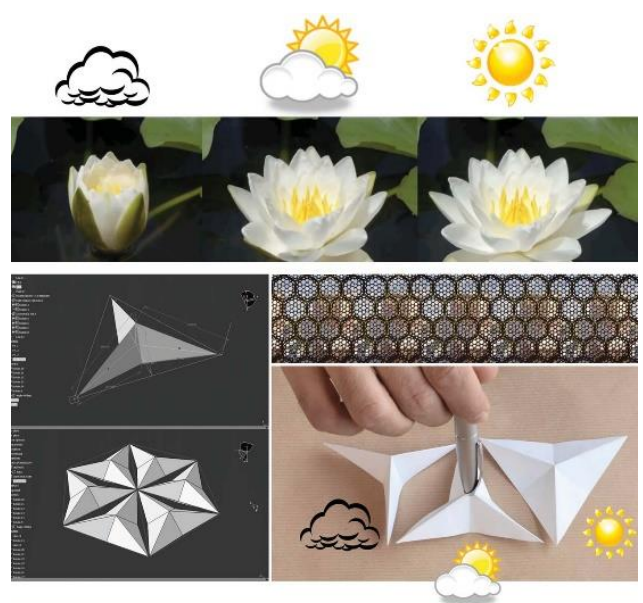

Figure 7: Dynamic Mashrabiya inspired from the past and from adaptive natural systems (Cilento, 2014) 
- The envelope layers

The building envelope is made of weather-tight glass curtain-wall and the Mashrabiya dynamic solar screen. The curtain-wall is comprised of unitized panels with a floor-to-floor height of $4200 \mathrm{~mm}$ and a variable width of $900 \mathrm{~mm}$ to $1200 \mathrm{~mm}$. The vision area of the curtain-wall from floor spans $3100 \mathrm{~mm}$. The innovative solar screen is spaced $2000 \mathrm{~mm}$ from the surface of the curtain-wall. (Oborn, 2013)

While The Mashrabiya has stainless steel supporting frames, aluminum dynamic frames, and fibreglass mesh infill. Each umbrella-like device is
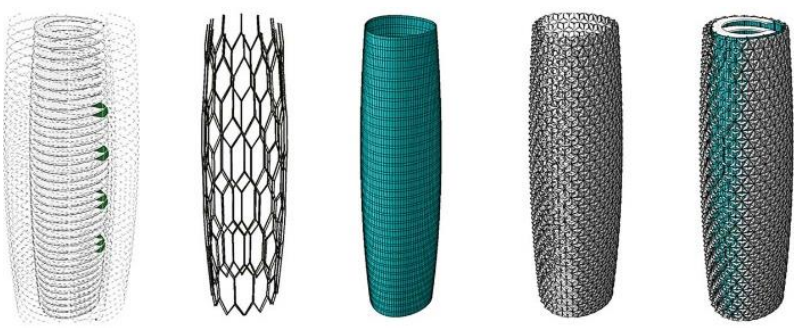

Figure 8: The components integration system of the building envelope (Cilento, 2014) assembled as a unitized system $4200 \mathrm{~mm}$ in height and varying between $3600 \mathrm{~mm}$ and $5400 \mathrm{~mm}$ in width. Each unit is sub-divided into six triangular frames that unfold through a centrally positioned actuator and piston. The largest unit weighs around $625 \mathrm{~kg}$. Cantilever struts fixed to the main structure of the building protrude through the curtain-wall to support the dynamic units. (Oborn, 2013)

- Mashrabiya units distribution

There are 1049 mashrabiya units fitted to each of the towers covering the East, South, and West zones. When a facade zone is subjected to direct sunlight, the Mashrabiya units in that zone will unfold into a closed state providing shading to the inner glazing skin. As the sun moves around the building each Mashrabiya unit will progressively open. (Oborn, 2013)

\section{- Performance Criteria}

The dynamic mashrabiya solar screen goal as shown in (Figure 5 ) is to block the direct solar rays from reach to the inside spaces during working hours, from 09:00 till 17:00 which reduces solar gain

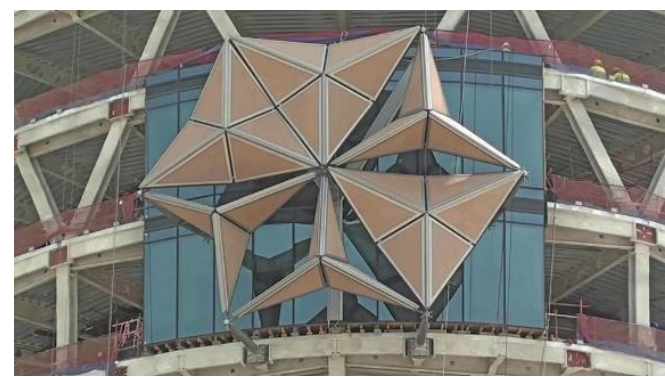

Figure 9: Mushrabiya units distribution on the building envelope

(Cilento, 2014) and control the solar glare. This dynamic system responds to the environmental changes, so the mashrabiya has a major impact on the amount of natural daylight and reduces the cooling loads required for air-conditioning than other solar screen systems. The benefits include increased visibility and privacy. The following is a brief description of the performance criteria, driving factors, and related benefits that the dynamic mashrabiya solar screen system off ers to the building. (Cilento, 2014)
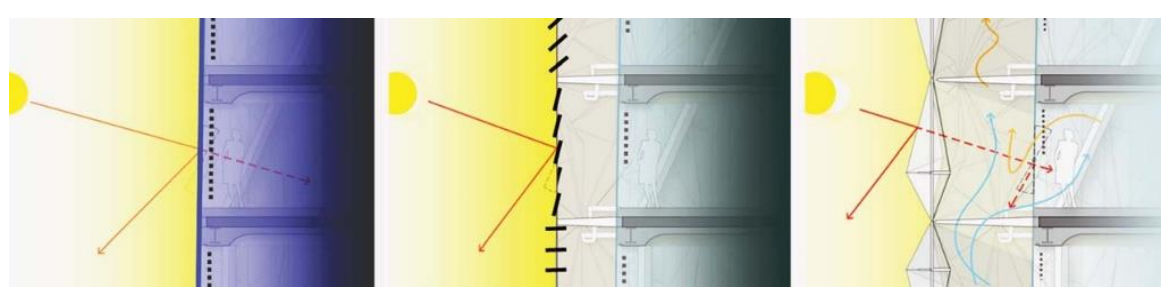

Figure 5: The comparison between the dynamic Mushrabiya and the other common systems. (Oborn, 2013)

Concerning the Solar gain and energy performance, the north façade exposes to direct direct solar rays only for a short time in the morning and later in the afternoon. Shading units in the North zone was, therefore, unnecessary. With the MEP team, a maximum solar gain of $400 \mathrm{~W} / \mathrm{m}$ was set for the curtain-wall and the shading screens were designed in front of zones that exceeded this limit. In the United Arab Emirates (UAE), 70\% to 85\% of the solar gain in typical towers is due to direct exposure to solar rays. The remaining is from direct energy exchange between internal and external environments. As a result, there was not much value in having an expensive curtain-wall with very low conductivity; hence the overall $\mathrm{U}$-value of the envelope was set at $2.0 \mathrm{Wm}^{2} / \mathrm{k}$. (Oborn, 2013) 

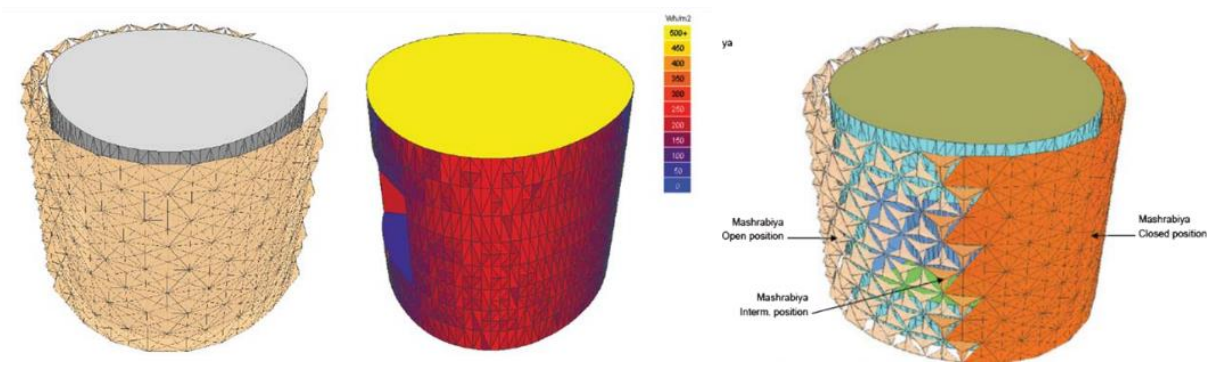

Figure 6: Shading studies were used to explore the impact on energy performance of different Mushrabiya configurations. (Cilento, 2014)

While concerning visibility and lighting, The target is to admit natural diff used light into the building and maintain a useful daylight threshold ranging from 250 to 2000 Lux throughout daily working hours (09:00 am to 17:00 pm). As soon as light sensors located at the perimeter of the ceiling near the curtain-wall read lower than 250 Lux, dimmers linked between the sensors and artificial lighting are activated to maintain the required comfort threshold. (Karanouh \& Kerber, 2015)

Finally concerning wind, A series of wind-tunnel tests were conducted at various scales to anticipate the combination of loads exerted on the building generally and on the mashrabiya locally. Both small and full-scale models have tested accordingly. The tests revealed that the fluid form of the building generated relatively low $+\mathrm{ve}$ and -ve pressures, averaging $1.5 \mathrm{kPa}$ up to a maximum of $3.5 \mathrm{kPa}$. A single dynamic unit was later subjected to very high wind speeds up to $90 \mathrm{~m} / \mathrm{s}$, deployed in diff erent opening positions, where the resulting pressures did not exceed the maximum figures applied on the building as a whole due to the fluid aerodynamic geometry of the building form and dynamic mashrabiya system. (Karanouh \& Kerber, 2015)

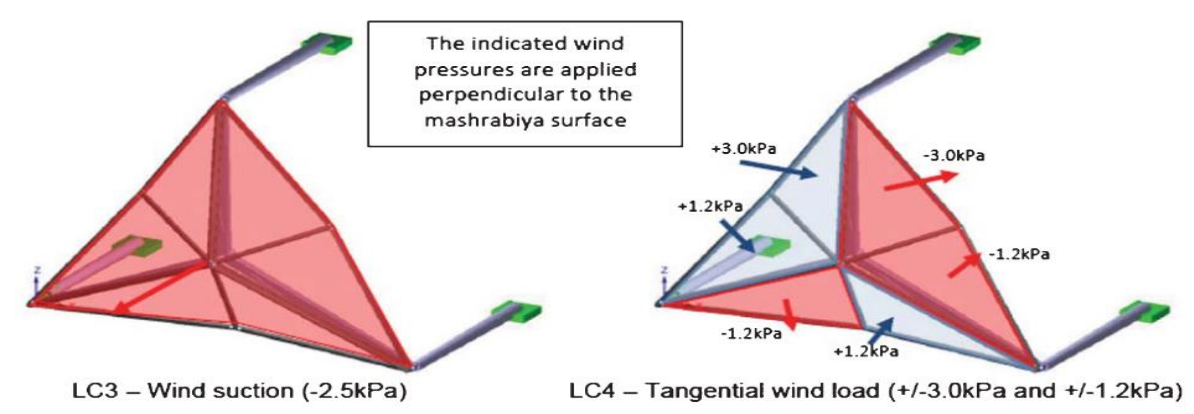

Figure 7: The results of wind tunnel tests reveal relatively low wind-loads due to the fluid geometry of the building and efficient form of the mashrabiya. (Karanouh \& Kerber, 2015) 


\subsection{ARAB WORLD INSTITUTE, (Institut du Monde Arabe), "IMA."}

ARCHITECTS: Jean Nouvel

PROGRAM: 25,000 square meters of museum, library, auditorium, conference and meeting rooms, cafeteria, and office S.

STRUCTURAL SYSTEM: metal structure; curtain walls.

MAJOR MATERIALS: Aluminum, glass.

\section{- OVERVIEW:}

In 1980, 18 Arab countries concluded an agreement with France to establish the Arabic World Institute. The main purpose was to provide information about the Arab world and set in motion detailed research to cover Arabic and the Arab world's cultural and spiritual values. (kinetic Architecture, 2000)

The design competition was won by Jean Nouvel, who is widely known for his particular surface treatment with "smart" materials, and with this kinetic facade for the Arab World Institute. The building was finished in 1988. (kinetic Architecture, 2000)

The building consists of 2 main volumes encompass an inner courtyard with the North mass rising nine stories and the southern portion rising to 11 stories. The interior spaces house numerous typologies including a restaurant, museum, library, offices, and auditorium. A multi-story glass atrium is wrapped with a steel staircase featuring exposed elevator lifts on the interior. The library

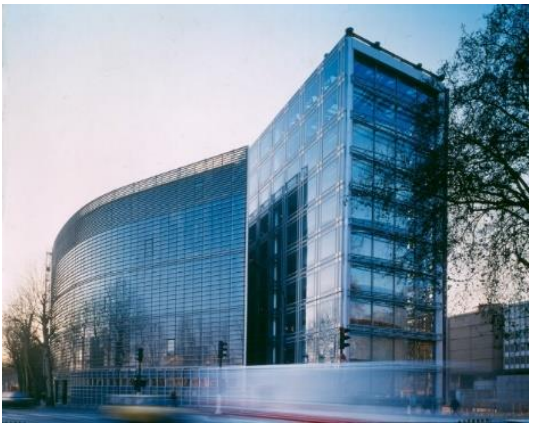

Figure 13: The Institute of Arab World in Paris and northern portion of the 4th-floor feature increased floor to ceiling heights as well as incorporating numerous terraces and a mezzanine. (Archdaily, 2008)

This project received the «Equerre d'Argent» prize in 1988 and an Aga Khan Award for Architecture in 1989. (ARCHITECTURE-STUDIO, 2010)

\section{- SITE ANALYSIS:}

The Arab World Institute is located on Rue des Fosses Saint Bernard in Paris, France. The building acts as a buffer zone between the Jussieu Campus of Paris VI University and the Seine. The river façade follows the curve of the waterway and helps reduce the hardness of a rectangular block, adapting itself to the view from the Sully Bridge. At the same time, the building also appears to fold itself back in the direction of the Saint Germain des Pres district. (Jean Nouvel, 2015)

The site is super central and in direct relationship with the former history of Paris. The architect opened the building three degrees to catch the spire of the church. The Skyline of view is the Cathedral Notre Dame with La Defense, and Pompidou Centre. (Archdaily, 2008)

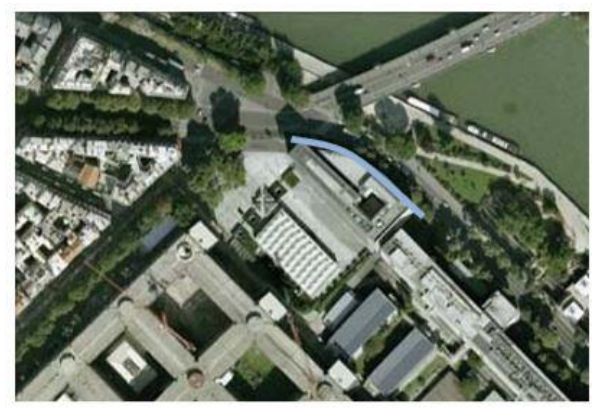

Figure 14: The Location of Arab World Institute

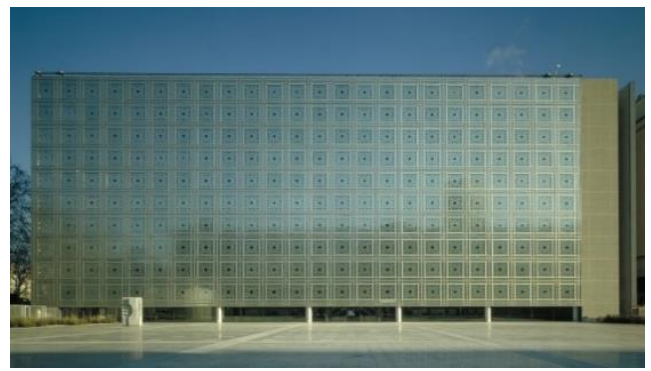

Figure 15: South Façade

\section{- CONCEPT:}

Typical of Jean Nouvel's work is his attention to façade detailing, and this design is no exception. The main feature and innovative element of the IMA is the advanced responsive metallic brise soleil on the south façade. Nouvel's proposal for this system was well received for its originality and its reinforcement of an archetypal element of Arabic architecture - the MUSHRABIYYA. He drew inspiration from the traditional lattice work that has been used for centuries in the Middle East to protect the occupants from the sun and provide privacy. (Archdaily, 2008)

Nouvel was able to synthesize traditional Arabic architectural e lements into a modern design that is evocative of the architecture of the Middle East. His use of light as a building block and modifier of space creates a deeper sense of place and enhances the overall experience. It continues to serve as a great beacon and location for the interaction of Arab culture. (Archdaily, 2008) 
"In Paris, between winter and summer, the light entirely changes, and that's why I proposed a rotating system that keeps geometry and allows having a Haussmann* façade with its closed shutters in summer and a Haussmann façade with the windows open in winter. Just to protect the building and to create also a kind of poetry of the reaction of the geometry in relationship to the light", says Jean Nouve. (Jean Nouvel, 2015)

* Haussmann's renovation of Paris was a vast public works program commissioned by Emperor Napoléon III and directed by his prefect of the Seine, Georges-Eugène Haussmann, between 1853 and 1870. It included the demolition of crowded and unhealthy medieval neighborhoods, the building of wide avenues, parks and squares, the annexation of the suburbs surrounding Paris, and the construction of new sewers, fountains, and aqueducts. Haussmann's work met with fierce opposition, and he was finally dismissed by Napoleon III in 1870, but work on his projects continued until 1927. The street plan and distinctive appearance of the center of Paris today is largely the result of Haussmann's renovation.

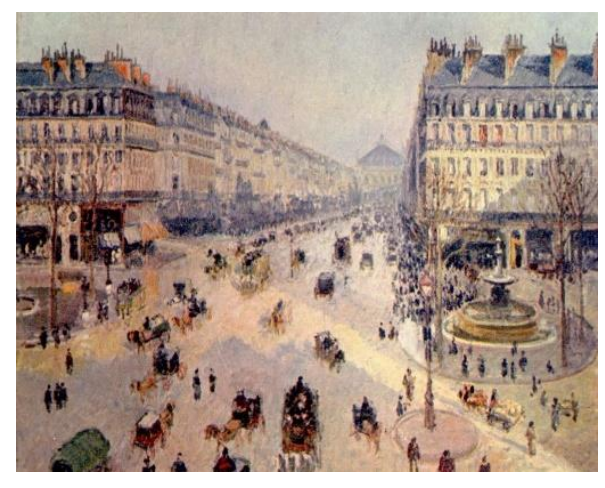

Figure 16: The Avenue de l'Opéra, created by Haussmann, painted

by Camille Pissarro (1898)

The Arab World Institute headquarters in Paris refers to several contextual aspects: traditional and modern neighborhoods, Arab culture and Western culture, modernity and history, inside spaces and outside areas. Its symbolic approach and modernity are based on a present-day interpretation of the history of both civilizations, Western and Eastern civilization. (ARCHITECTURE-STUDIO, 2010)

The site is situated at the junction of two urban areas, a traditional (continuous) one and a modern (discontinuous) one. The building creates a bond between these two types of urban planning. The Northern facade, facing historical Paris, covers up the museum and expresses the relationship between exhibits and the city, transposed by a silkscreen design on the facade. The Southern facade covers the library and uses the traditional patterns of Arab artistic geometry "MASHRABIYYA". (ARCHITECTURE-STUDIO, 2010)

\section{- TECHNIQUE OF APPLICATION:}

The architect designed a facade to respond to changing environments. The south facade of the building consists of high-tech photosensitive mechanical devices which control the light levels and transparency. It interprets traditional wooden Arab latticework screens into a glass and steel construction with 30,000 light-sensitive diaphragms on 1600 elements, which operate as a lens of a camera. The changes to the irises are revealed internally far more than what can be observed from the exterior. "Visitors should know that this building is Arabian," says Nouvel. (kinetic Architecture, 2000)
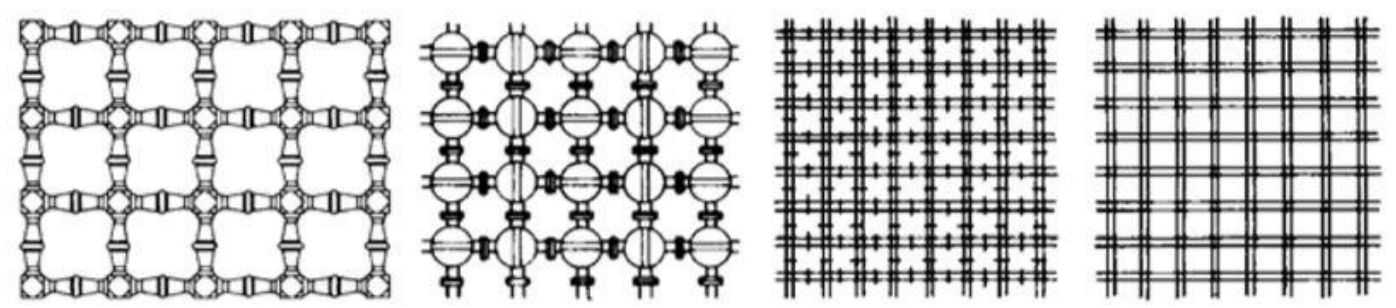

Figure 17: Different Forms of Mushrabiya

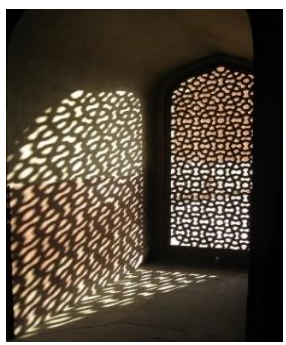

Figure 18:

A Mushrabiya Windnw

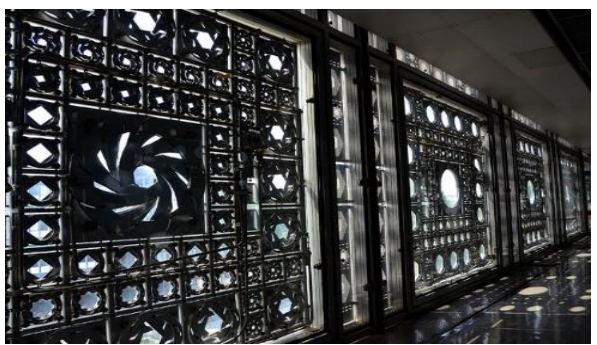

Figure 19: South Façade from interior

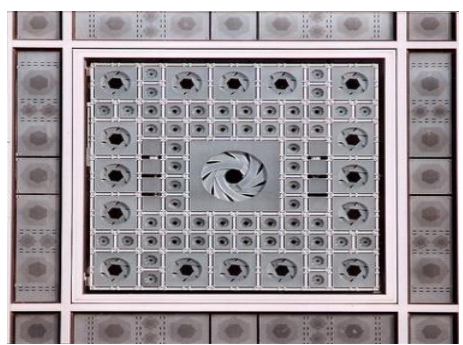

Figure 20: A Single Panel on the South Facade 
A paved plaza provides an element of separation from the relative University de Jussieu and the main volume of the building. Further enhancing the outdoors spaces is the paving that mimics the patterning of the façade. Recessed ground lights complement the light play that emanates from the interior of the structure at night. (Archdaily, 2008)

\section{- DYNAMIC MASHRABIYA:}

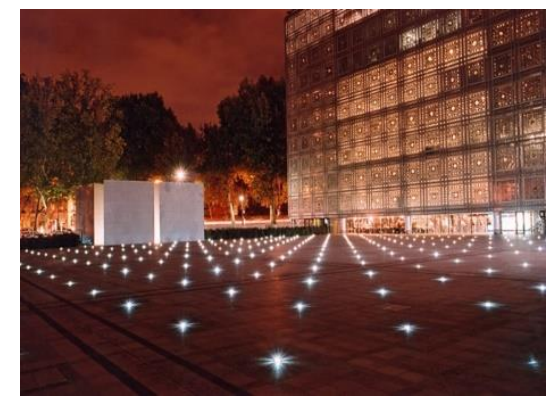

Figure 21: The outdoor Plaza

The system of MASHRABIYYA incorporates several hundred light sensitive diaphragms that regulate the amount of light that is allowed to enter the building. During the various phases of the lens, a shifting geometric pattern is formed and showcased as both light and void. Squares, circles, and octagonal shapes are produced in a fluid motion as light is modulated in parallel. Interior spaces are dramatically modified, along with the exterior appearance. While these ocular devices create an incredible aesthetic, they are functional from an environmental controls standpoint as well. Solar gain is easily mitigated by closing or reducing the aperture sizes. (Archdaily, 2008)

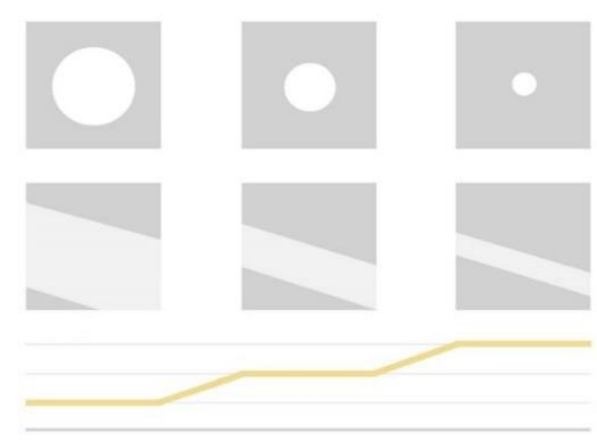

Figure 22: Diaphragms, Light and Shadoa

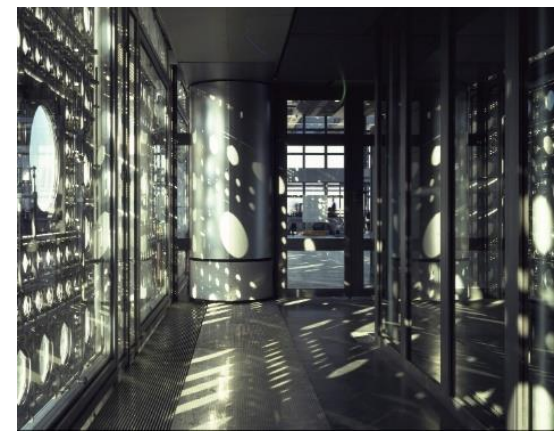

Figure 23: Daylights in Interior
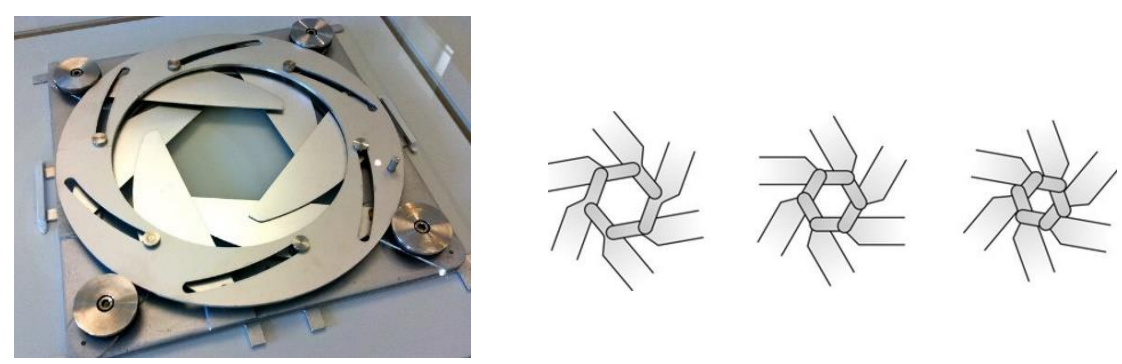

Figure 24: Model of the mechanical unite that forms the dynamic Mushrabiya

\section{- PERFORMANCE CRITERIA:}

The unique use of high-tech photosensitive mechanical devices made this building famous in 1987. Nowadays it's still widely known and hasn't lost its futuristic impression, but the facade system no longer works. Nonetheless, the south facade is quite beautiful. The facade and the carefully planned sequence between the entrance onto the plaza and the entrance of the building set up interesting scale relationships. (kinetic Architecture, 2000) 


\section{Aya A. EL.Taweel, Aliaa A. Mahmoud "The Technology Application Aspect in Optimiz...”}

\section{Discussion}

Analysing these two example draws attention to the obvious transformation of utilizing MASHRABIYYA concept, as it has more functions in the modern Islamic architectural design as following in table 2.

Table 2: The Mushrabya Upgrading

\begin{tabular}{|c|c|c|c|}
\hline \multicolumn{2}{|c|}{ Project } & functions & Strategy \\
\hline \multirow{9}{*}{ 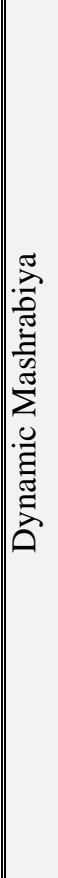 } & \multirow{6}{*}{ 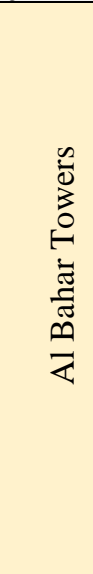 } & Provides either shade or light avoiding dark & $\begin{array}{l}\text { Comprised way of its triangular units like origami } \\
\text { umbrellas } \\
\text { Shading screen transformation }\end{array}$ \\
\hline & & Better admission of natural diff used light. & $\begin{array}{l}\text { These techniques including using Algorithms, } \\
\text { parametric design }\end{array}$ \\
\hline & & Reducing solar gain & Air-Cooling Skin \\
\hline & & $\begin{array}{l}\text { Concerning the Solar gain and energy } \\
\text { performance }\end{array}$ & \multirow{3}{*}{$\begin{array}{l}\text { Building Information Modelling (BIM), and } \\
\text { production automation have integrated into the } \\
\text { AEC industry }\end{array}$} \\
\hline & & While concerning visibility, and lighting & \\
\hline & & $\begin{array}{l}\text { Concerning wind, A series of wind-tunnel tests } \\
\text { were conducted at various scales to }\end{array}$ & \\
\hline & \multirow{3}{*}{ 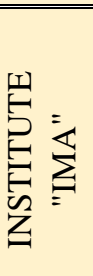 } & Control the light levels and transparency & High-tech photosensitive mechanical devices \\
\hline & & Solar gain is easily mitigated & By closing or reducing the aperture sizes \\
\hline & & $\begin{array}{l}\text { Interior spaces are dramatically modified, } \\
\text { along with the exterior appearance. }\end{array}$ & $\begin{array}{l}\text { Squares, circles, and octagonal shapes are } \\
\text { produced in a fluid motion }\end{array}$ \\
\hline
\end{tabular}

Through these results can it knock the door for upgrading the traditional design elements to benefit from the modern technology in smart way which achieves luxury and sustainability with keeping the Arab identity. This research recommends the conscious usage of Islamic pattern in design elements like (Mushrabiya), as it shouldn't be confined to ornamenting facades and interiors, but also keep and upgrade its role in the whole design aspects.

\section{REFERENCES}

(2000). Retrieved from kinetic Architecture: http://www.kineticarchitecture.net/

(2010). Retrieved from ARCHITECTURE-STUDIO: http://www.architecture-studio.fr/en/

(2015). Retrieved from Jean Nouvel: http://www.jeannouvel.com/

Abas, S., \& Salman, A. (1995). Symmetries of Islamic Geometrical Patterns. World scientific.

Abd ElSalam, M. (2012). THE USE OF SMART GEOMETRY IN ISLAMIC PATTERNS. 6th ASCAAD Conference 2012 CAAD| INNOVATION| PRACTICE (p. 49). Bhzad Sidawi.

Abdullahi, Y., \& Embi, M. (2013). Evolution of Islamic geometric patterns. Frontiers of Architectural Research, 2, 243251.

Aljamali, A. M., \& Banissi, E. (2004). Grid method classification of Islamic geometric patterns. In Geometric Modeling: Techniques, Applications, Systems and Tools (pp. 233-254). Springer.

Archdaily. (2008). Retrieved from http://www.archdaily.com/

Cilento, K. (2014). Al Bahar Towers Responsive Facade/Aedas. Retrieved January, 13.

Jehan, m. (2015). THE TRADITIONAL ARTS AND CRAFTS OF TURNERY OR MASHRABIYA. Rutgers.

Karanouh, A., \& Kerber, E. (2015). Innovations in dynamic architecture. Journal of Facade Design and Engineering, $3(2), 185-221$.

Oborn, P. (2013). Al Bahr Towers: The Abu Dhabi Investment Council Headquarters. John Wiley/\& Son. 